\title{
Kewirausahaan Berbasis Komunitas : Model Bisnis untuk Pengelolaan Aset dan Infrastruktur
}

\author{
Community Based Enterprise : A Business Model for Asset and \\ Infrastructure Management
}

\author{
Veny Megawati ${ }^{1, a)}$, Aluisius Hery Pratono ${ }^{1, b)}$, Teguh Wijaya Mulya ${ }^{2, c)}$ \& Delta Ardy \\ Prima $^{3, \mathrm{~d})}$ \\ ${ }^{1)}$ Fakultas Bisnis dan Ekonomika, Universitas Surabaya. \\ ${ }^{2)}$ Fakultas Psikologi, Universitas Surabaya. \\ ${ }^{3)}$ Fakultas Teknik, Universitas Surabaya.
}

Koresponden : ${ }^{a)}$ veny.megawati@staff.ubaya.ac.id, ${ }^{b}$ hery_pra@staff.ubaya.ac.id, c)teguh@staff.ubaya.ac.id, \& ${ }^{d)}$ delta@staff.ubaya.ac.id

\begin{abstract}
ABSTRAK
Artikel ini bertujuan untuk mengidentifikasi bisnis model dalam pengelolaan wilayah berupa ruang terbuka hijau yang merupakan fasilitas umum yang dimiliki sebuah desa. Analisis ini menggunakan pendekatan phenomenology, di mana peneliti terlibat langsung sebagai volunteer sehingga memungkinkan untuk memahami bagaimana masyarakat mengelola ruang terbuka hijau di Kecamatan Trawas Mojokerto Jawa Timur. Hasil temuan kami menunjukkan bahwa model bisnis kewirausahaan sosial yang berbasis komunitas mengelola ruang terbuka hijau dengan beberapa prinsip, antara lain (1) mengembangkan inovasi sosial untuk memecahkan masalah lingkungan, (2) memanfaatkan karakter lokasi yang untuk menghasilkan produk dan layanan baru, (3) memanfaatkan jaringan untuk mendapatkan ide pengembangan produk dan jasalayanan, serta (4) mendorong keterlibatan untuk mendapatkan dukungan dari masyarakat yang lebih luas. Penelitian ini berkontribusi pada teori layanan publik dengan menggabungkan konsep kewirausahaan sosial dan teori pengelolaan lokasi.
\end{abstract}

Kata Kunci : manajemen aset infrastruktur, kewirausahaan sosial, inovasi produk

\section{PENDAHULUAN}

Pengelolaan suatu wilayah selalu dikaitkan dengan asset publik, infrastruktur dan fasilitas untuk meningkatkan kualitas hidup masyarakat (Quin, 2018) . Konsep pengelolaan aset publik, infrastruktur, dan fasilitas dalam suatu wilayah merupakan upaya membangun reputasi, namun bagi negara berkembang seperti Indonesia, keterbatasan sumberdaya selalu menjadi kendala utama bagi pengelolaan wilayah (Manning \& Sumarto, 2011). Pengelolaan aset, infrastruktur, dan fasilitas juga menentukan akses masyaraka tterhadap akses layanan publik (Pratono \& Maharani, 2018). Oleh karena itu, keterlibatan masyarakat perlu diwujudkan dalam bentuk pengembangan unit usaha untuk membiayai pengelolaan aset, infrastruktur dan fasilitasi di suatuwilayah.

Tujuan Utama Manajemen Aset Infrastruktur dan Fasilitas adalah untuk mengelola suatu Infrastruktur dan Fasilitas agar selalu bisa berfungsi dengan baik (function sustainability), sesuai dengan Standar Pelayanan Minimum (SPM), secara ekonomis, efisien, efektif, serta bisa selalu bersifat green (sustainable). Segala resikoseyogyanya diperhitungkan dengan baik, agar Infrastruktur dan Fasilitas selalu bermanfaat bagi para pemangku kepentingan. Hal ini baru akan bisa diwujudkan kalau Organisasi Pengelola Infrastruktur dan 
Fasilitas bisa berfungsi dengan baik (Soemitro\& Suprayitno 2018; Suprayitno \& Soemitro 2018). Oleh karena itu pengkajian Organisasi Pengelola merupakan hal penting.

Kajian penelitian sebelumnya menunjukan bahwa sebagian besar pengelolaan aset, infrastruktur, dan fasilitas merupakan kebijakan yang hanya bersifat tambalsulam, yang gagal menciptakan solusi yang lebih baik (Lombard, 2014). Penelitian lain di China, India dan negara berkembang lain, pengelolaan asset, infrastruktur, dan fasilitas hanya untuk mencegah terjadinya arus sumberdaya manusia keluardaerah (Musterd \& Kovács, 2013). Pengelolaan aset, infrastruktur, dan fasilitassering kali dilihat sebagai sebuah cost-center, yang sering kali tidak layak secara keuangan (Medway, et al., 2016). Kewirausahaan sosial mencoba menjawab pertanyaan tersebut untuk memecahkan masalah keterbatasan sumberdaya keuangan, terutama ketika dukungan keuangan dari pemerintah pusat dan lembaga donor berkurang secara drastis (Pratono, Pramudija, \& Sutanti, 2016).

Penelitian ini bertujuan untuk memahami perananorganisasi bisnis berbasis komunitas dalam mengelola asset publik, infrastruktur maupun fasilitas umum dengan menggabungkan konsep kewirausahaan sosial dan manajemen tempat. Penelitian ini menggunakan pendekatan induktif dengan menggunakan studi kasus pengelolaan lapangan terbuka hijau di Trawas Mojokerto Jawa Timur.

\section{LITERATURE REVIEW}

Tempat atau wilayah menunjukan sebuah "setting" di mana orang-orang berkarya dan berproduksi termasuk di dalamnya ada organisasi bisnis maupun sosial (Warnaby \& Medway, 2013) . Tempat menjadi sebuah fenomena bagi studi tentang geografi humanistis yang menempatkan manusia sebagai pusat kegiatan (Gregory, et al., 2009; Seamon\& Lundberg, 2017), sehingga pengelolaan tempat merupakan revitalisasi ruang publik yang melibatkan partisipasi masyarakat setempat (Cilliers, et al., 2015; Medway, et al., 2016).

Kerjasama dan koordinasi berbagai kepentingan berdasarkan pendekatan wilayah menjadi elemen utama dalam manajemen tempat atau wilayah, melalui pemanfaatan skil, pengalaman, maupun sumberdaya (Institute of Place Management, 2018). Partisipasi masayarakat bermuara pada keseimbangan peranan model social dalam melayani masyarakat di suatu tempat (Sommerville \& McElwee, 2011). Upaya memperkuat hubungan social dalam masyarakat akan menciptakan kesempatan terbentunya lembaga yang mampu berkontribus iterhadap masyarakat maupun warisan yang ditinggalkannya (Beck \& Brooks, 2019).

Di lain pihak, kewirausahaan berbasis komunitas merupakan Lembaga bisnis yang dimiliki masyarkat untuk mewujudkan kesejahteraan masyarakat tersebut (Peredo \& Chrisman, 2006). Ratten \& Welpe (2011) menekankan pentingnya tujuan organisasi tersebut dengan menciptakan nilai-nilai keberlajutan yang di dalamnya ada unsure politik, sosial, dan ekonomi. Kewirausahaan berbasis komunitas merupakan salah satu model kewirausahaan sosial yang mempunyai karakteristik komersial, bertujuan untuk memecahkan masalahsosial, serta tata kelola yang partisipatif (Defourny \& Nyssens, 2017). Ketika suatu wilayah mempunyai aktivitas produksi dan konsumsi (Medway, et al., 2017), kewirausahaan berbasis komunitas akan terlibat dalam pengelolaan asset publik, infrastruktur dan fasilitas umum pembentukan sarana produksi dan konsumsi yang berorientasi pada kesejahteraan masyarakat (Dentoni, et al., 2018).

Kewirausahaan berbasis komunitas nampaknya relevan untuk pengelolaan asset publik, infrastruktur dan fasilitas umum karena berorientasi pada penguatan serta mobilisasi masyarakat supaya menjadi pemain aktif di wilayah tersebut (Vestrum, 2014). Tentunya kegiatan pengelolaan infrastruktur dan fasilitas public dengan mengandalkan organisasi bisnis mempunyai risiko ekonomi karena mengandalkan mekanisme pasar ketika kewirausahaan konvensional gagal memecahkan masalah kemiskinan dan pengangguran (Kay, et al., 2016; Pratono \& Tjahjono, 2017). Sebuah tempat mempunyai karakter yang unik ketika mampu 
menciptakan berbagai inovasi yang menjadi motor bagi pengembangan sebuah model bisnis untuk mengatasi masalah sosial di tempat tersebut (Porter, et al., 2017).

Lembaga bisnis berbasis komunitas berlokasi di suatu tempat namun terhubung dengan lingkungan yang lebih luas. Pengaruh dari berbagai pemangku kepentingan dalam pengambilan keputusan serta pendekatan manajemen partisipatif merupakan karakteristik utama dalam kewirausahaan sosials (Defourny \& Nyssens, 2017) . Keterlibatan para pemangku kepentingan sangat penting dalam mewujudkan keberlanjutan lembaga ini melalui proses berbagai pengetahuan yang akan mendorong pengembangan skil serta akses mendapatkan sumber daya (Sankaran \& Demangeot, 2017).

Ketika suatu wilayah ditentukan oleh jejaring yang melibatkan pusat kota maupun kawasan pinggiran, perkembangan wilayah tergantung dari jejaring yang terdapat dalam program pembangunan masyarat (Jeong, et al., 2016). Pada saat yang sama, jejaring juga bias menimbulkan persaingan antara mereka yang ingin mempertahankan daya saing wilayahnya dan mereka yang ingin mengembangkan kawasannya (Kahler, 2009). Tidak heran, suatu kawasan merupakan hasil persaingan yang cukupdinamis (Pierce, et al., 2011), yang melibatkan berbagai pemangku kepentingan baik internal maupun eksternal serta jaringan inter-sektoral maupun intra-sektoral (Pratono, et al., 2017).

\section{METODE PENELITIAN}

Untuk memahami peranan organisasi bisnis berbasis komunitas dalam mengelola asset publik, infrastruktur maupun fasilitas umum dengan menggabungkan konsep kewirausahaan sosial dan manajemen tempat, penelitian ini menggunakan pendekatan penomenologi di mana peneliti terlibat di dalamnya. Posisi peneliti sebagai volunteer dalam Program Pengabdian Masyarakat yang didanai oleh KemenristekDikti dan Universitas Surabaya. Pendekatan tersebut memungkinkan penulis mendapatkan akses informasi baik dengan berinteraksi dengan pemain utama maupun melalui pengamatan untuk memahami konteks (Smith, et al., 2009).

\section{Kondisikawasan yang diamati}

Desa Ketanrame terletak di Kecamatan Trawas, yang merupakan bagian selatan Kabupaten Mojokerto, Jawa Timur. Pada umumnya ketinggian wilayah kecamatan di Kabupaten Mojokerto rata-rata $64 \mathrm{~m}(<500 \mathrm{~m})$ di atas permukaan laut, dan hanya Kecamatan Pacet dan Trawas merupakan daerah yang memiliki ketinggian yang berbeda dari kecamatan lain yaitu Kecamatan Pacet $470 \mathrm{~m}$ dan Kecamatan Trawas $600 \mathrm{~m}$ di ataspermukaanlaut. Kawasan inimerupakanwilayah pegunungan yang subur dengan suhu udara yang cukup sejuk, sehingga menjadi kawasan wisata. Populasi vila dan hotel cukup tinggi.

Masyarakat Desa Ketapanrame mayoritas adalah petani, peternak dan pedagang. Desa Ketapanrame merupakan desa yang paling ujung di Kabupaten Mojokerto yang berbatasan dengan Kabupaten Pasuruan. Jarak dari Pusat Pemerintahan Desa ke Kecamatan Trawas $\pm 0,5$ $\mathrm{Km}$ dan ke Kabupaten Mojokerto $\pm 45 \mathrm{Km}$. Dilihat dari tingkat sebarannya, penduduk Trawas mencapai $2,71 \%$ atau relative lebih kecil dibandingkan kecamatan lainnya yang rata-rata mencapai 5\%. Misalnya di Kecamatan Jetis mencapai 7,65\% dan Ngoro sebesar 7,18\% dari total penduduk.

\section{Pengumpulan Data}

Pengumpulan data terbagi dalam dua tahap. Tahap pertama fokus pada membangun relasi antara partisi pandangan peneliti. Kami menyebut responden sebagai partisipan, karena konsep dan gagasan yang disampaikan diharapkan berasal dari mereka. Peneliti menggunakan jejaring yang sudah dikembangkan oleh Lembaga Penelitian dan Pengabdian Masyarakat 
Universitas Surabaya. Lembaga ini sudah lama menjalin berbagai kerjasama dengan masyarakat di Kecamatan Trawas.

Tahap kedua adalah mengidentifikasi responden, yang dipilih berdasarkan kemampuannya menyediakan informasi. Pertama, responden tipe pertama adalah pemimpin lokal yang mempunyai peran penting dalam pengelolaan aset, infrastruktur, dan fasilitas. Responden tip ekedua adalah pengelola yang melaksanakan aktivitas pengelolaan dalam kegiatan sehari-hari. Tipe ketiga adalah pemangku kepentingan, yaitu pejabat dan tokoh masyarakat yang turut terlibat dalam proses pengambilan keputusan.

Untuk mendorong responden mau membagikan pengalaman serta mengelaborasi fenomena berdasarkan perspektif mereka, peneliti secara hati-hati mengadaptasi pertanyaan yang terbuka dan sesuai dengan konteks dan masalah yang dihadapi. Pendekatan ini dipercaya mampu mengatisipasi pernyataan dan cerita yang muncul tanpa diprediksi namun mampu menyediakan informasi yang berguna (Zhang \& Guttormsen, 2016).

\section{Analisis data}

Analisis hasil wawancara semi terstruktur yang mendalam menggunakan pendekatan interpretative. Tahap pertama, peneliti fokus untuk mengidentifikasi fragmen data untuk mengeksplorasi arah teori yang bias dimunculkan. Peneliti mengelompokan data kedalam beberapa konsep yang berbeda untuk menginvestigasi fenomena yang terjadi.

Analisis berikutnya mencermati fragmen-fragmen tersebut kedalam berbagai kategori mengikuti proses interpretasi di mana peneliti mencoba membuat label istilah, yang mendekati istilah asli yang disebutkan oleh para partisipan. Dalam penelitian kualitatif, pendekatan ini disebut sebagai theoretical sampling, yang membandingkan konsep berdasarkan hasil wawancara, hasil diskusi, catatan lapangan, serta studi literature (Randall \& Mello, 2012).

Data analisis juga melibatkan proses triangulasi baik dengan observasi referensi, wawancara dan focus group diskusi. Pendekatan tersebut dilakukan supaya penelitian ini mampu menyajikan gambaran fenomena yang seimbang dan obyektif, serta memenuhi prinsip metode cross-validation (Miles \& Gilbert, 2005). Pada akhirnya, hasil analisis interpretative didukung oleh hasil wawancara yang disajikan secara verbatim (Smith, et al., 2009).

\section{HASIL TEMUAN}

Berawal dari impianmasyarakat untuk bias menikmati air bersih, maka melalui Program dari Pemerintah pada tahun 1978 melalui tim Pembangunan Kecamatan dibangunlah sarana air bersih berupa pemasangan pipa dan pembuatan bak penampungan air yang dialirkan untuk memenuhi kebutuhan air minum warga meskipun saat itu masih belum sepenuhnya sesuai harapan masyarakat. Dalam perjalanannya selama sepuluh tahun akhirnya tebentuklah Unit usaha "Tirto Tentrem" tahun 1988 dengan maksud agar kebutuhan air minum masyarakat bias terlayani dan dikelola dengan baik.

Dengan adanya suatu wadah pengelolaan yang teroganisir melalui Tirto Tentrem konsumennya semakin banyak dan berkembang pesat yang menghasilkan omset besar sehingga sempat di ambilalih pengelolaanya oleh PDAM tahun 1997 sampai 1999 yang akhirnya dikembalikan pengelolaannya ke Desa pada tahun 2000. Selanjutnya dengan adanya Otonomi Daerah maka Pada Tahun 2001 terbentuklah BUMDes (Badan Usaha MilikDesa) dengan nama BPAM "TirtoTentrem" yang merupakan cikal bakal BUMDesa Ketapanrame yang waktu itu masih mengelola pendistribusian dan pelayanan air minum kemasyarakat.

Dalam perkembangannya karena banyak potensi-potensi baru yang perlu diwadahi maka BUMDes BPAM "Tirtotentrem" mengembangkan usahanya dengan membentuk beberapa sektor/unit usaha baru dan namanya berubah menjadi Bumdesa Ketapanrame pada tahun 2010 dengan mengelola 4 sektor usaha: (1). pengelolaan Air Minum kemasyarakat, (2). 
Penjualan air minum melalui mobil Tangki, (3). Pengelolaan sampah, dan (4). Sektor pengelolaan kios Desa yang sampai tahun 2016 terjadi penambahan dua sector yakni pengelolaan kandang ternak dan wisata desa.

Pada bagian berikutnya akan dijelaskan tentang criteria kewirausahaan sosial yang memanfaatkan peluang bisnis pada daerah yang diamati. Penelitian ini mengidentifikasi bagaimana kewirausahaan berbasis komunitas tersebut mampu mengelola aset, infrastruktur, dan fasilitas yang ada di desa.

\section{Mengembangkan inovasi bisnis untuk mengurangi ketergantungan pada penghasilan dari sumberdaya alam}

Kecamatan Trawas menghadapi potensi konflik sumberdaya air. Populasi vila dan hotel dengan kebutuhan air yang makin meningkat dan makin mengancam wilayah konservasi air yang juga dibutuhkan oleh masyarakat. Kecamatan yang terdiri atas 13 desa itu makin dipenuhi sejumlah penginapan yang dan lokasi peristirahatan serta wisata yang terus didatangi pengunjung. Setidaknya empat desa masing-masing DesaTrawas, Kasiman, Ketapanrame, dan Tamiajeng merupakan desa yang relative padat dengan bisnis vila dan penginapan dan terjadi kecenderungan untuk saling berebut sumber air yang berasal dari air terjun Dlundung, Trawas, Mojokerto yang merupakan bagian dari Gunung Botak dengan terusan pada Gunung Welirang. Untuk Desa Trawas saja, sekitar 200 vila atau penginapan komersial beroperasi dengan relative ramai.

"[...] Desa kami saat ini masih mengandalkan air sebagai sumber penghasilan utama untuk membiayai berbagai pembangunan. Sekarang persaingan dari usaha (explorasi) air sudah sangat ketat. Hampir setiap desa menjual air dari kawasan ini. Oleh karena itu, kami berusaha mengembangkan desa pariwisata sebagai alternative sumber penghasilan bagi desa."

"[...] Kawasan ini dulu adalah tanah bengkok. Tanah milik desa yang bias dikelola oleh perangkat. Bagi desa lain, perangkat desa bias mendapatkan gaji dari tanah bengkok. Mereka biasanya mengembangkan tanaman yang berpenghasilan tinggi. Tapi di kawasan ini, tidak ada tanaman yang cocok. Sehingga kami mengembangkan menjadi kawasan wisata."

\section{Mengembangkanproduk yang mempunyai karakteristik wilayah dengan} bekerjasama dengan pemangku kepentingan

Karakteristik sebuah kawasan menawarkan potensi untuk dikembangkan berupa sebuah produk atau jasa yang tentunya diharapkan mampu membantu memecahkan masalah social di kawasan tersebut (Porter, et al., 2017). Pengelolaan sebuah kawasan menunjukan kemampuan memproduksi barang dan jasa serta menarik konsumen untuk mendukung pencapaian tujuan sebuah kawasan. Demikian juga dengan keberadaan kawasan pariwisata di Trawas.

"[...] Trawas merupakan kawasan pariwisata yang paling dekat dengan Surabaya. Jadi kami memilih mengembangkan tanah bengkok ini menjadi sebuah alun-alun yang menjadi pusat kegiatan serta pertunjukan senibudaya".

"[...] Kalau Anda ke kawasan pariwisata Trawas, pasti melalui desa kami. Desa kami merupakan pintu gerbang kawasan pariwisata Trawas. Membangun alun-alun ini bias menjadi semacam "landmark"."

\section{Mengandalkan tata kelolapemerintahan yang partisipatif untuk mendapatkan} dukungan sumberdaya.

Tata kelola yang bersifat partisipatif tidak begitu saja bias diterapkan. Masingmasing pemangku kepentingan dituntut memberikan kontribusi. Tanpa kontribusi rasanya sulit menempatkan pemangku kepentingan sebagai pengambil keputusan. Tata 
kelola yang partisipatif memungkinkan lembaga mendapatkan kredibilitas, maupun akses jejaring yang akan bermanfaat pengembangan pengelolaan wilayah.

Dalam penelitian ini, pengelola lapangan terbuka hijau di Trawas membuka diri terhadap kehadiran Pemerintah Kabupaten Mojokerto, yang berkontribusi terhadap pembangunan awal. Demikian juga terhadap lembaga pendidikan seperti Universitas Surabaya, yang diharapkan berkontribusi terhadap pengembangan pengelolaan wilayah hijau tersebut. Masyarakat yang terlibat juga mereka yang punya kepentingan, termasuk kelompok kesenian yang berkenan menyumbang penampilannya untukmembuat ruang terbuka hijau tersebut lebih menarik. Demikian juga dengan para pengelola industry makanan dan jasa parkir yang berkontribusi terhadap kebutuhan para pengunjung.

"[...] Kami tidak menyangka respon masyarakat begitu tinggi terhadap keberadaan alun-alun ini. Bukan hanya akhir pekan, bahkan setiap sore kawasan ini ramai dikunjungi orang. Kami perlu mempersiapkan tata kelolanya supaya lebih mampu menjawab tantangan baru yang muncul."

"[...] Tahap awal kegiatan ini adalah menjaring aspirasi masyarakat sebanyak mungkin. Jadi kita perlu mendengarkan pendapat dari tokoh-tokoh masyarakat setempat dan mengidentifikasi berbagai potensi konflik kepentingan yang mungkin bias muncul."

"[...] Sangat penting kiranya untuk mengidentifikasi harapan masyarakat terhadap pembangun analun-alun ini. Tentunya hal tersebut dilakukan dengan mengidentifikasi siapa yang menjadi pemilik project ini, siapa yang menyediakan sumberdaya, dan siapa yang akan mengklaim keberhasilan tersebut."

\section{Memanfaatkan jejaring untuk mendapatkan dukungan dari pengunjung atau pelanggan}

Jejaring bisnis memungkinkan kewirausahaan berbasis komunitas tersebut mampu menyesuaikan diri dengan perubahan lingkungan bisnis. Melalui jejaring pasar, organisasi bisnis tersebut mengajak komunitasnya untuk terlibat bisnis dengan komunitas lain. Kemampuan penjualan akan berkembang melalui kombinasi antara jejaring bisnis dan kemampuan untuk memecahkan masalah.

"[...] Kami di Mojokerto sebenarnya mempunyai berbagai kelompok sadar wisata, yang setiap bulan bertemu. Salah satu wacana yang dihasilkan adalah membuat paket kunjungan wisata yang terintegrasi, sehingga pengunjung mempunyai banyaki nformasi dan pilihan untuk berwisata di TrawasMojokerto."

"[...] Desa kami merupakan penghasil teh dan kopi. Kami mencoba berkoordinasi dengan pengelola kawasan hijau ini untuk menyediakan tempat bagi produk-produk local tersebut, sehingga produk-produk tersebut bukan hanya dipasarkan di luar negeri tetapi juga bias dinikmati masyarakat lokal."

"[...] Di tempat kami sedang mencoba membangkitkan pariwisata dengan mengangkat kembali sejarah Majapahit. Saat ini kami sedang berkoordinasi supaya ada paket tour yang memungkinkan pengunjung di Trawas juga bias hadir di desa kami."

\section{KESIMPULAN}

Keterkaitan antara konsep kewirausahaan social berbasis komunitas dengan konsep pengelolaan wilayah bias menghasilkan konsep-konsep baru bagi pengelolaan aset, infrastruktur, dan fasilitas. Hasil penelitian ini berkontribusi terhadap diskusi tentang identifikasi bisnis model bagi pengelolaan wilayah. Kajian ini mengidentifikasi peranan keinginan untuk mengembangkan wilayah dengan pengembangan ekonomi yang menentukan bagaimana sebuah bisnis bias berkontribusi dalam pengelolaan wilayah (Porter, et al., 2017).

Penelitian ini mengkaji sebuah studi kasus tentang bagaimana sebuah organisasi bisnis berbasis masyarakat yang berusaha mengembangkan sebuah wilayah dengan mengelola asset, infrastruktur, dan fasilitas yang dimiliki oleh sebuah desa untuk merevitalisasi sebuah desa. 
Lembaga ini menciptakan kondisi di mana kualitas hidup masyarakat bisa meningkat dengan ketersediaan ruang terbuka hijau. Temuan ini mengkonfirmasi kajian Defourny\& Nyssens (2017), yang meyakini bahwa kewirausahaan social hadir untuk membantu memecahkan masalah social dengan membuat suatu tempat menjadi lebih nyaman untuk ditinggali oleh warganya.

Kedua, prinsip-prinsip. Dalam kewirausahaan social telah berkontribusi dalam tata kelola wilayah dari proses inovasi hingga proses pengambilan keputusan yang memungkinkan lembaga usaha berbasis masyarakat menjadi agen perubahan sosial. Aksi kolektif memungkinkan masyarakat memanfaatkan modal sosial yang mereka punya untuk mendapatkan akses pasar. Temuan ini menkonfirmasi penelitian sebelumnya yang berpendapat bahwa kewirausahaan social mendorong perubahan social dengan memanfaatkan jejaring antara masyarakat lokal dan pemangku kepentingan (Vestrum, 2014).

Penelitian ini mengkonfirmasi kajian sebelumnya yang berpendapat bahwa kewirausahaan social berbasis masyarakat berperan penting dalam menciptakan keseimbangan modal sosial di suatu wilayah (Sommerville \& McElwee, 2011; Beck \& Brooks, 2019) dengan mengembangkan proses produksi dan konsumsi alternatif (Dentoni, et al., 2018). Namun demikian, temuan ini berbeda dengan tipikal organisasi bisnis di kawasan pedesaan, yang mengandalkan pasar internal dan kurang berhasil dalam mencapai target dibandingkan perusahaan lain (Pato \& Teixeira, 2018).

Dengan menggunakan pendekatan interpretative, penelitian ini menunjukkan bagaimana sebuah lembaga usaha berbasis masyarakat mampu menempatkan diri dalam pengelolaan asset sebuah desa dengan mengembangkan infrastruktur dan fasilitas untuk mewujudkan kesejahteraan masyarakat. Hasil penelitian ini berkontribusi pada pemahaman pengelolaan wilayah dengan mengembangkan prinsip-prinsip dalam kewirausahaan sosial. Tulisan ini berpendapat bahwa kewirausahaan social bukan hanya membahas dimensi kewirausahaan, tujuans osial, serta tata kelola pemerintah yang partisipatif (Defourny \& Nyssens, 2017) tetapi juga mengakomodasi kepentingan wilayah khususnya yang memerlukan jejaring dengan struktur birokrasi pemerintahan yang ada. Kami percaya bahwa mempelajari kewirausahaan social bias membantu mengembangkan perspektif pengelolaan asset suatu wilayah, yang di dalamnya terdapat infrastruktur dan fasilitas. Penelitian ini merupakan penelitiankualitatif yang masih memerlukan jastifikasi dengan pendekatan empirik. Hasil penelitianini juga masih memerlukan konfirmasi dari penelitian berikutnya yang membahas tentang keterkaitan kewirausahaan sosial dan pengelolaan wilayah.

CATATAN. Terima kasih kepada Kementrian Riset dan Teknologi Direktorat Jenderal Pendidikan Tinggi (RISTEKDIKTI) yang telah membiayai kegiatan penelitian dan pengabdian masyarakat ini.

\section{DAFTAR PUSTAKA}

Beck, D. \& Brooks, S. (2019). "Social enterprise and the development of cultural heritage assets as catalysts for urban place-making”, In: Calabrò, F; Della Spina, L; Bevilacqua, C (Ed.), New Metropolitan Perspectives. ISHT 2018. Smart Innovation, Systems and Technologies, Berlin: Springer, pp. 308-315.

Cilliers, E. J., Timmermans, W., van den Goorbergh, F. \& Slijkhus, J. S. (2015). "Designing public spaces through the lively planning integrative perspective". Environment, Development, and Sustainability, Vol. 17 No.6, pp. 1367-1380.

Defourny, J. \& Nyssens, M. (2017). "Mapping social enterprise models: some evidence from the "ICSEM" project". Social Enterprise Journal, Vol. 13 No.4, pp. 318-328.

Dentoni, D., Pascucci, S., Polner, K. \& Gartner, W. B. (2018). "Learning "who we are" by doing: Processes of co-constructing prosocial identities in community-based enterprises". Journal of Business Venturing, Vol. 33 No.5, pp. 603-622. 
Gregory, D. et al. (2009). The Dictionary of Human Geography. Wiley-Blackwell Publishing. London.

Institute of Place Management (2018). What is Place Management?. Available at: http://www.placemanagement.org/ [Accessed 210 2018].

Jeong, Y-Y., Moon, T-H. \& Han, J. H. (2016). "A typology of network city in a socioeconomically disadvantaged region". City, Culture and Society, Vol. 7 No.3, pp. 161168.

Kahler, M. (2009). Networked Politics: Agency, Power, and Governance. Cornell University Press.Ithaca.

Kay, A., Roy, M.J. \& Donaldson, C. (2016). "Re-imagining social enterprise". Social Enterprise Journal, Vol. 12 No. 2, pp. 217-234.

Lombard, M. (2014). "Constructing ordinary places: Place-making in urban informal settlements in Mexico". Progress in Planning, Vol. 94, pp. 1-53.

Manning, C. \& Sumarto, S. (2011). "Employment, living standards and poverty: Trends, policies and interactions", In Manning, C.; Sumarto, S. (Eds.): Employment, Living Standards and Poverty in Contemporary Indonesia. Institute of Southeast Asian Studies, pp. 1-22. Singapore.

Medway, D., Parker, C., Quinn, S. \& Robert, G. (2016). "Changing place; placing change”. Journal of Place Management and Development, Vol. 9 No. 1. https://doi.org/10.1108/JPMD-02-2016-0007.

Medway, D., Roberts, G. \& Parker, C. (2017). "Editorial”. Journal of Place Management and Development, Vol. 10 No.1, pp. 2-6.

Miles, J. \& Gilbert, P. (2005). A Handbook of Research Method for Clinical and Health Psychology. Oxford University Press. Oxford.

Musterd, S. \& Kovács, Z. (2013). Place-making and policies for competitive cities. WileyBlackwell. Sussex.

Pato, L. \& Teixeira, A.A.C. (2018). "Rural entrepreneurship: The tale of a rare event". Journal of Place Management and Development, Vol. 11 No.1, pp. 46-59.

Peredo, A.M. \& Chrisman, J.J. (2006). "Toward a theory of community-based enterprise". Academy of Management, Vol. 31 No. 2, pp. 309-328.

Pierce, J., Martin, D. G. \& Murphy, J. T. (2011). "Relational place-making: the networked politics of place". Transactions, Vol. 36 No. 1, pp. 54-70.

Porter, I. D. et al. (2017). "The world towns framework: A call to action". Journal of Place and Development, Vol. 10 No.5, pp. 504-520.

Pratono, A.H., Pramudija, P. \& Sutanti, A. (2016). "Social enterprise in Indonesia: Emerging models under transition government”. ICSEM Working Paper No.36. Liege, Belgia: The International Comparative Social Enterprise Model (ICSEM) Project.

Pratono, A.H. \& Tjahjono, G. (2017). "How does materialistic attitude influence the impact of corporate brand on the customers' intention to donate to corporates' charity?". Humanomics, Vol. 33, No. 4, pp 484-498.

Pratono, A. H., Suyanto, Marciano, D. \& Zurbrügg, C. (2017). "Social return on investment for community-based enterprise in Surabaya City". The Hong Kong Journal of Social Work, Vol. 51 No. 1/2, pp. 93-114.

Pratono, A.H. \& Maharani, A. (2018). "Long-term care in Indonesia: The role of integrated social post for elderly". Journal of Aging and Health, Vol. 30 No. 10, pp. 1556-1573.

Quin, S. (2018). Managing Places Special Interest Group, Available at: www.placemanagement.org/special-interest-groups/managing-places/ [Accessed 1 October 2018]. 
Randall, W. S. \& Mello, J. E. (2012). "Grounded theory: An inductive method for supply chain research". International Journal of Physical Distribution \& Logistic Management, Vol. 42 No. 8/9, pp. 863-880.

Ratten, V. \& Welpe, I. M. (2011). "Guest editorial: Special issue: Community-based, social and societal entrepreneurship". Entrepreneurship \& Regional Development, Vol. 23 No. 5/6, pp. 283-286.

Sankaran, K. \& Demangeot, C. (2017). "Conceptualizing virtual communities as enablers of community-based entrepreneurship and resilience". Journal of Enterprising Communities: People and Places in the Global Economy, Vol. 11 No. 1, pp. 78-94.

Seamon, D. \& Lundberg, A. (2017). "Humanistic Geography". International Encyclopedia of Geography: People, the Earth, Environment and Technology, Vol. 6, pp. 1-11.

Smith, J. A., Flowers, P. \& Larkin, M. (2009). Interpretative Phenomenological Analysis: Theory, Method, and Research. Sage. London.

Soemitro, R.A.A. \& Suprayitno, H. (2018). "Pemikiran Awal tentang Konsep Dasar Manajemen Aset Fasilitas". Jurnal Manajemen Aset Infrastruktur \& Fasilitas, Vol. 2, Suplemen 1, Juni 2018, Hal : 1-13.

Sommerville, P. \& McElwee, G. (2011). "Situating community enterprise: A theoretical exploration". Entrepreneurship \& Regional Development, Vol. 23 No. 5-6, pp. 317-330.

Suprayitno, H. \&Soemitro, R.A.A. (2018). "PreliminaryReflexionon Basic Principleof Infrastructure AssetManagement". Jurnal Manajemen Aset Infrastruktur \& Fasilitas, Vol. 1, No. 1, Maret 2018, Hal. : 1-9.

Vestrum, I. (2014). "The embedding process of community ventures: creating a music festival in a rural community". Entrepreneurship \& Regional Development, Vol. 26 No. 7-8, pp. 619-644.

Warnaby, G. \& Medway, D. (2013). "What about the 'place' in place marketing”. Marketing Theory, Vol. 13 No. 3, pp. 345-362.

Zhang, L. E. \& Guttormsen, D. S. (2016). “'Multiculturality' as a key methodological challenge during in-depth interviewing in international business research". Cross Cultural \& Strategic Management, Vol. 23 No. 2, pp. 232-256. 
(e)ISSN 2615-1847 $\quad$ (p)ISSN 2615-1839

Jurnal Manajemen Aset Infrastruktur \& Fasilitas - Vol.3, No.2, September 2019 